\title{
Goitre or lodine Deficiency Disorder - There is More Than Meets the Eye
}

Iodine deficiency is the world's most widespread, yet easily preventable, cause of brain damage. Iodine is an essential element that is needed for the production of thyroid hormones, thyroxine (T4) and triiodothyronine (T3) which are critical for the normal growth and development, and well being of all humans. Iodine was discovered by Courtois in 1811 as a violet vapor arising from seaweed ash while manufacturing gunpowder for Napoleon's army. Gay-Lussac identified it as a new element, and named it iodine, from the Greek for "violet." Iodine was found in the thyroid gland by Baumann in $1895 .{ }^{1}$

The body does not make iodine and is dependent on dietary sources; making it is an essential part of our diet. The healthy adult human body contains 15-20 mgs of iodine, of which about $70-80 \%$ is in the thyroid gland. The normal intake and requirement of iodine is $100-150 \mathrm{mcg}$ per day. Iodine is rapidly absorbed through the gut and excess iodide is readily excreted by the kidney. The level of iodine excretion correlates well with its intake, so that it can be used to assess the level of intake. The thyroid gland has to trap about $60 \mathrm{mg}$ of iodine per day to maintain an adequate supply of thyro.xine for the body.

In nature, most of iodine exists in the ocean. A large amount of iodine is leached from the soil surface by glaciation, snow or rain, and carried by rivers and floods into the sea. Generally, the older an exposed soil surface, the more likely it will be leached of iodine. The most likely areas to be leached of iodine are the mountainous areas of the world like, the Himalayas, the Andes, the European Alps and the vast mountains of china. All crops grown in these soils will be iodine deficient. As a result, human and animal population which are dependent on food grown in such soil also become iodine deficient. The iodine content of plants grown in iodine deficient soils may be as low as $10 \mathrm{mcg}$ per $\mathrm{kg}$ compared to $1 \mathrm{mg}$ per $\mathrm{kg}$ dry weight in plants grown in iodine replete soil. Iodine deficiency in affected population will continue unless supplements are provided, or alternatively diversification of the diet occurs with an increase in iodine intake derived from food sources outside the iodine deficient areas.

In 1917, Marine and Kimball showed that thyroid enlargement (goiter) was caused by iodine deficiency and could be prevented by iodine supplementation which was introduced in Switzerland and the United States in the early 1920s through iodization of salt. ${ }^{2}$ But, Iodine deficiency does not cause a mere enlargement of thyroid gland (endemic goitre), it can cause a variety of disorders including, hypothyroidism, endemic cretinism, still births, mental retardation, defects in vision, hearing and speech, spasticity, and neuromuscular weakness; collectively called Iodine deficiency disorders (IDD). However, of far greater significance is IDD's less visible, yet pervasive, mental impairment that reduces intellectual capacity at home, in school and at work. The adoption of the term 'iodine deficiency disorders' reflects a new dimension of understanding of the full spectrum of the effects of iodine deficiency on the fetus, the neonate, the child, the adolescent and the adult in the whole population. ${ }^{3}$

Iodine deficiency has been identified all over the world. It is a significant health problem in 130 countries and affects 740 million people. One third of the world population is exposed to the risk of IDD. The first global estimate from the World Health Organization (WHO) on the prevalence of goiter was reported in $1980 .{ }^{4}$ It estimated that $20 \%$ to $60 \%$ of the world's population was iodine deficient and/or goitrous, with most of the burden in developing countries. ${ }^{3}$ India alone, It is estimated that, more than 6.1 crore people are suffering from endemic goiter and 88 lakh people are mental/ motor handicaps. A national level survey, carried out in 25 states and 5 union territories in the country found that out of 282 districts surveyed, it is a major public health problem in 241 districts where the prevalence rate is more than $10 \%$. It is estimated that more than 71 million persons are suffering from goiter and other iodine deficiency disorders like mental retardation, deaf-mutism, squint, and neuromotor defects. ${ }^{5}$ 
Jammu and Kashmir is a state particularly affected by iodine deficiency. An extensive survey on school children spanning three years (1993-1995) revealed that $45.2 \%$ of children were having thyroid enlargement and quantitation of urinary iodine excretion demonstrated iodine deficiency. ${ }^{6}$ In some highland areas of the Valley, goitre prevalence was as high as $70 \%$ to $77 \% .{ }^{7,8}$ Further studies revealed wide availability and consumption of non-iodized salt along with lack of awareness about IDD in the Valley; only one third of the population in the Valley were consuming iodized salt.

In the recent years, considerable attention has been paid to iodine deficiency in public health programs in most countries. In Kashmir Valley also, a massive campaign was initiated by the Department of Endocrinology at Sher-iKashmir Institute of Medical Sciences Srinagar for implementation of existing National IDD control program. This was done by invigorating the government machinery and civil society; enforcing the official ban on availability and sale of non-iodized salt in the Valley. An awareness campaign regarding the magnitude of IDD (and its possible alleviation through salt iodization) was launched through print and electronic media among the public in general and medical community in particular. These efforts undeniably improved the iodine sufficiency status in Kashmir Valley as reflected in the recently conducted post-iodozation survey by the Department. ${ }^{10}$ The results of the study showed total goitre prevalence has reduced to around $4 \%$ in Kashmir Valley with a mean $( \pm$ SEM) urinary iodine excretion of $123 \pm 6 \mu \mathrm{g} / \mathrm{g}$. creatinine.

Despite considerable improvement in iodine sufficiency state overall, residual goitre is still seen in many surveys conducted in postiodization pase..$^{11-13}$ These surveys report a residual goitre prevalence of $13.5 \%$ to $23 \%$. Persistent, albeit reduced prevalence of goitre, despite adequate iodine prophylaxis, suggests existence of additional factors like selenium deficiency, iron deficiency, presence of goitrogens like thiocyanates in the environment, autoimmunity, etc. However, presence of underlying subtle iodine insufficiency should always be kept in mind in such situations. In this issue of the journal, there is a study by Gupta, et al. from Postgraduate Department of Community Medicine, GMC Jammu about the current goitre prevalence in various districts of Jammu Province. The authors, using cluster sampling methodology, screened 10800 school children, aged 6-12 years for presence goitre and graded them clinically as per joint recommendation of WHO/ UNICEF/ICCIDD. The study found a total goitre rate (TGR) of $24.9 \%$, varying from $21.7 \%$ in the predominantly urban Jammu district to $26.8 \%$ in predominantly rural Samba district. The main limitation of the study, as mentioned by the authors, is that they did not assess the adequacy of iodine in salt or measure urinary excretion of iodine in the surveyed population. Therefore, it cannot be said with certainty that this high prevalence of goiter in Jammu province is due to iodine deficiency, other micronutrient deficiencies, autoimmunity or higher presence of goiterogens in the environment. $^{11-15}$

Methods for assessment of iodine deficiency include measurement of urinary iodine concentration, goitre, newborn thyroid-stimulating hormone, and blood thyroglobulin though most authors use goitre prevalence along with urinary iodine estimation. For measuring goiter, there are two methods: 1) neck inspection and palpation; and 2) thyroid ultrasonography. However, palpation of goiter in areas of mild iodine deficiency has poor sensitivity and specificity; in such areas, measurement of thyroid volume by ultrasound is preferable. ${ }^{16}$ Thyroid ultrasound is noninvasive, quickly done (2-3 min per subject), and feasible even in remote areas using portable equipment. However, interpretation of thyroid volume data requires valid references from iodine-sufficient children. Besides, in a resourceconstrained country like ours, where ultrasonography may not be available everywhere, we have to still rely on palpation method to detect goitre. Once goitres are reported in a particular community, one needs to look at other components of iodine deficiency as it may be a tip of the iceberg and not a mere thyroid enlargement. Especially, one needs to look at the pattern of salt consumption in that community and ensure that there is no sale and supply of non-iodized salt in the area.

In the present day, we have an outstandingly simple, universally effective, wildly attractive and incredibly cheap technical weapon for eliminating IDD, i.e., use of iodized salt. After a couple of decades of universal salt iodization (USI), iodine nutrition of the people has considerably improved. USI has been an effective, safe and convenient measure to control and prevent IDD. In order to achieve the goal of IDD sustained elimination, the USI Programme should be persisted and the quality of iodized salt provided to the beneficiaries should be monitored continuously. Preventive public health measures need to be augmented in area along with strengthening of monitoring and surveillance of IDD. In addition, emphasis needs to be given on health education, if we are to eliminate this most common yet easily preventable, cause of brain damage. Today, we are on the threshold of eradicating iodine deficiency in the world. This is an achievement that will be hailed as a major public health success in the history of mankind.

Shariq Masoodi, MD, DM

Additional Professor,

Department of Endocrinology,

SKIMS Srinagar (J\&K), India-190011

(Executive Editor, JMS) 


\section{References}

1. Baumann F. Ueber das normale Vorkommen von Jod im Thierkörper.Z Physiol Chem 1896;21:319-30.

2. Marine D, Kimball OP. The prevention of simple goiter in man.J Lab Clin Med 1917;3:40-48.

3. Zimmermann MB. Iodine deficiency. Endocr Rev 2009; 30(4): 376.

4. Zimmermann MB, Jooste PL, Pandav CS. The iodine deficiency disorders. Lancet 2008;372:1251-62

5. National Iodine Deficiency Disorders Control Programme. http://www.nihfw.org/NDC/DocumentationServices/Natio nalHealthProgramme/NationalIodineDeficiencyDisorders. html (last visited 13 May 2012).

6. Zargar AH, Shah JA, Mir MM, Laway BA, Masoodi SR, Shah NA. Prevalence of goiter in school children in Kashmir valley. Am JClin Nutr 1995;62 (5):1020-1.

7. Zargar AH, Shah JA, Laway BA, Masoodi SR, Shah NA, Mir MM. Epidemiology of Goitre in school children in Rural Kashmir (Pulwama district). Journal of Indian Medical Sciences Academy 1997;10(1):13-14.

8. Zargar AH, Shah JA, Laway BA, Masoodi SR, Shah NA, Mir MM. Goiter survey in schoolchildren in Kupwara (Kashmir Valley). Indian Pediatrics 1996;33:247-9.
9. Zargar AH, Sofi FA, Masoodi SR, Laway BA, Shah NA, Wani AI, Masoodi MI. Pattern of salt consumption and awareness about iodine deficiency disorders in Kashmir Valley. IDD Newsletter 1996;12(3):46-8.

10. Ali A, Zargar AH, Masoodi SR, Mudasar S. Goiter survey (A Pilot Study - Iodine Status revisited). Thesis Submitted to Sheri-Kashmir Institute of Medical Sciences, Srinagar for the Award of Doctor of Medicine (M.D) 1999, pp 86.

11. Marwaha RK, Tandon N, Gupta N, Karak AK, Verma K, Kochupillai N. Residual goitre in the postiodization phase: iodine status, thiocyanate exposure and autoimmunity. Clin Endocrinol 2003; 59:672.

12. Wang Y, Zhang Z, Ge P, Wang Y, Wang S. Iodine deficiency disorders after a decade of universal salt iodization in a severe iodine deficiency region in China. Indian J Med Res 2009; 130:413-17.

13. Das S, Bhansali A, Dutta P, et al. Persistence of goitre in the post-iodization phase: micronutrient deficiency or thyroid autoimmunity? Indian J Med Res 2011;133:103-9.

14. Brauer VF, Schweizer U, Kohrle J, Paschke R. Selenrium and goiter prevalence and borderline iodine sufficiency. Eur J Endocrinol 2006;155:807-12.

15. Hess SY, Zimmermann MB, Adou P, Torresani T, Hurrell RF. Treatment of iron deficiency in Goitrous children improves the efficacy of iodized salt in Cote d' Ivoire. AmJ Clin Metr 2002;75.743-8. 